\title{
Lifetime Predictions of Toxic and Radioactive Waste Disposal and Remediation Schemes
}

\author{
David J. Wesolowski ${ }^{1}$, Rodney C. Ewing ${ }^{2}$ and Jordi Bruno ${ }^{3}$
}

\footnotetext{
${ }^{1}$ Chemical Sciences Division, Oak Ridge National Laboratory, Oak Ridge, TN 37831-6110, USA

${ }^{2}$ Department of Geological Sciences, University of Michigan, 425 E University Ave., Ann Arbor, MI 48109, USA

${ }^{3}$ Sustainability and Waste Management, Universitat Politécnica Catalunya, 08034, Barcelona, Spain
}

Over the past few centuries, technological and societal advances have resulted in explosive growth of a human population with increasing material appetites, creating a world in which resources are clearly limited, energy and materials utilization have global environmental and political impacts, and geohazards (earthquakes, volcanic eruptions, tsunami's, landslides, etc.) affect ever-growing numbers of people. One of the Grand Challenges for geochemists in the $21^{\text {st }}$ Century will be to contribute to the transformation of geoscience from a largely observational and explanatory science, into a science that is capable of making reliable predictions at levels of accuracy and over time scales that are useful in formulating public policy and even personal decisions, such as where to live, how to avoid calamity, and how to accommodate the limitations of a finite Earth. Designing safe disposal and remediation strategies for wastes from mining and energy production is clearly an arena in which geochemical experiments, theories and models will play a pivotal role.

Toward that end, the authors organized what turned out to be a highly successful and well-attended symposium, with the same title as this article, at this year's $15^{\text {th }} \mathrm{V} . \mathrm{M}$. Goldschmidt Conference in Moscow, Idaho (GCA, v.69, no.10S, p. A408-430, 2005). Forty six presenters from countries throughout the world participated in the two-day event, which featured three keynote and sixteen invited talks and posters, including six student presentations. Participation was greatly aided by the generous sponsorship of this event by: the U.S. Department of Energy's Office of Civilian Radioactive Waste Management - Science, Technology and International (OST\&I) program; The Electric Power Research Institute's High Level Waste Repository Issue Resolution program; and UT-Battelle, LLC. Their sponsorship also subsidized a pre-conference field trip (Figures $1-5)$ to the Yucca Mountain High Level Nuclear Waste Repository Site (May 18,19, 2005), lead by Wesolowski, Zhongbo Yu (University of Nevada, Las Vegas), Abe Van Luik (U.S. DOE) and John Stuckless (U.S. Geological Survey).

Nuclear power production epitomizes the need for predictive geoscience (Ewing, 2004). Current global carbon emissions of $\sim 7 \mathrm{Gt} / \mathrm{y}$, largely from fossil fuel consumption, are expected to grow and result in a variety of adverse global effects, including acid rain, toxic smog, and hypothetically, sea level rise and increased frequency and severity of adverse weather conditions. One of the most reliable and sufficiently large alternative sources of energy is nuclear power, which currently provides about $17 \%$ of the world's electricity, equivalent to a reduction in carbon emissions of $\sim 0.5 \mathrm{Gt} / \mathrm{y}$. The U.S. currently consumes $\sim 40 \%$ of the world's fossil fuel production, but generates only about $20 \%$ of it's electricity from nuclear plants. One major factor inhibiting increased power 
production form this source in the U.S. is the lack of a licensed repository for spent nuclear fuel, and Yucca Mountain is the only site being considered at this time.

The licensing issue hinges on DOE's ability to present a credible case before the Nuclear Regulatory Commission that releases of radionuclides from the repository will not pose a threat to the accessible environment. This case is being built using a performance assessment model that incorporates a thermochemical database (EQ3/6) fed by experiments and theoretical developments in aqueous geochemistry and fluid rock interactions, coupled reaction/transport models which combine both the chemical and physical aspects of fluid and heat transport through porous and fractured media, geohazard and climate change models, and information gleaned from natural analogs. The assessment period is currently 10,000 years, but this has recently been challenged in a court of law, and may be extended to 300,000 years or more.

Yucca Mountain has a design capacity that only marginally exceeds the current U.S. inventory of commercial spent fuel, currently stored on site at power plants through the country. Some analysts suggest that in order to have a significant impact on global carbon emissions, worldwide nuclear and other carbon-free energy sources would have to increase tenfold by 2050 . If this increase came entirely from electrical power plants using the once-through nuclear fuel cycle, about 3,500 new 1-GW plants would be needed, that would generate enough spent fuel to fill a Yucca Mountain-sized repository every year. Though this extreme scenario is not likely to unfold, it seems inevitable that we need this source of energy, if the public can be assured that the operation of these plants, and the disposal of the wastes generated from their operation, can be made acceptably safe.

The Yucca Mountain field trip provided an excellent opportunity for a diverse cross section of engineers and geoscientists to gain a clearer perspective on the nature and problems related to this particular type of repository. The symposium not only brought together a similar broad cross section of scientists and engineers, but provided a forum for comparing and contrasting different repository designs being considered throughout the world, different methods of assessing their performance characteristics, and the surprisingly broad array of geochemical inputs needed in order to succeed in this Grand Challenge.

Reference Cited:

R.C. Ewing, Environmental Impact of the Nuclear Fuel Cycle", in (R. Giere and P. Stille, Eds.) Energy, Waste and the Environment: a Geochemical Perspective, The Geological Society of London, London, pp. 7-23 (2004). 


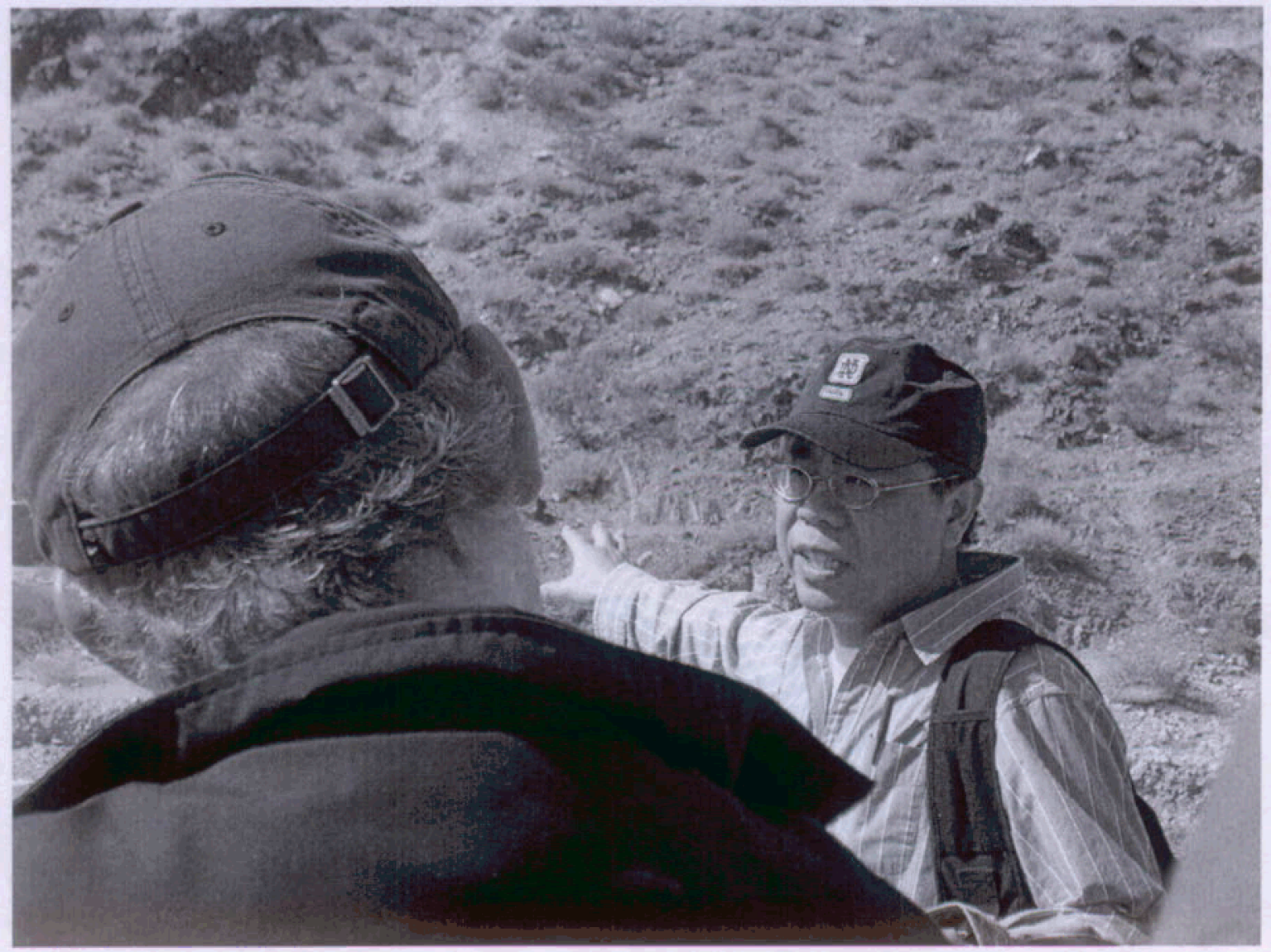

Figure 1. Dr. Zhongbu Yu, professor of hydrogeology at the University of Nevada, Las Vegas, describes the regional geology and hydrology of the Las Vegas and Yucca Mountain region, while electrochemist Don Gervasio (Arizona State University) looks on. Don wore his jacket during the entire field trip, in $90^{\circ} \mathrm{F}$ weather, apparently cool by Tempe standards! 


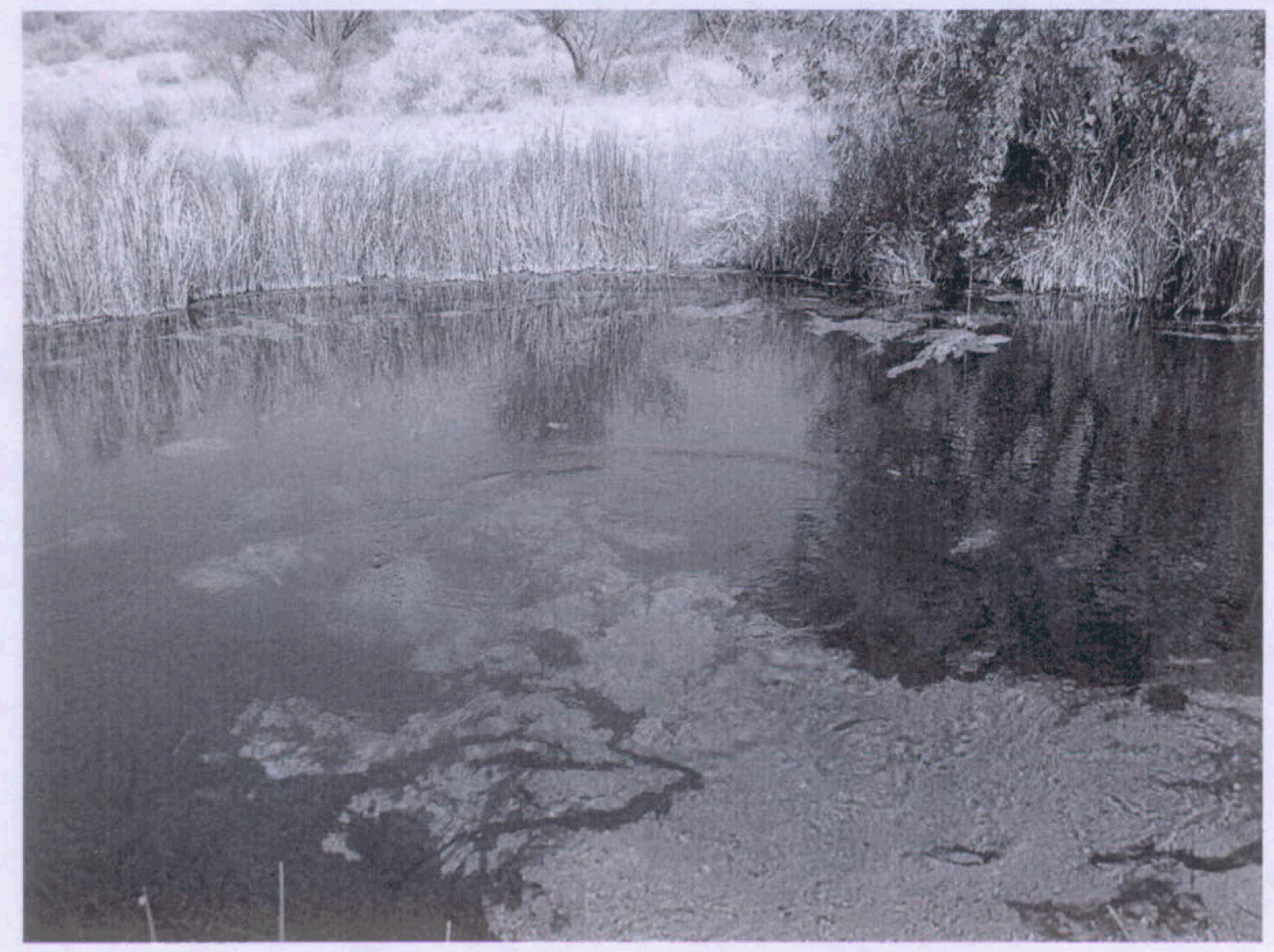

Figure 2. Pristine oases like Crystal Springs (above) and nearby Devil's Hole are home to the endangered Ash Meadows pupfish. These fault-controlled discharges are surface manifestations of groundwater flow from the mountains in the vicinity of Yucca Mountain, some 10 miles to the northeast, toward nearby Death Valley, their final destination. 


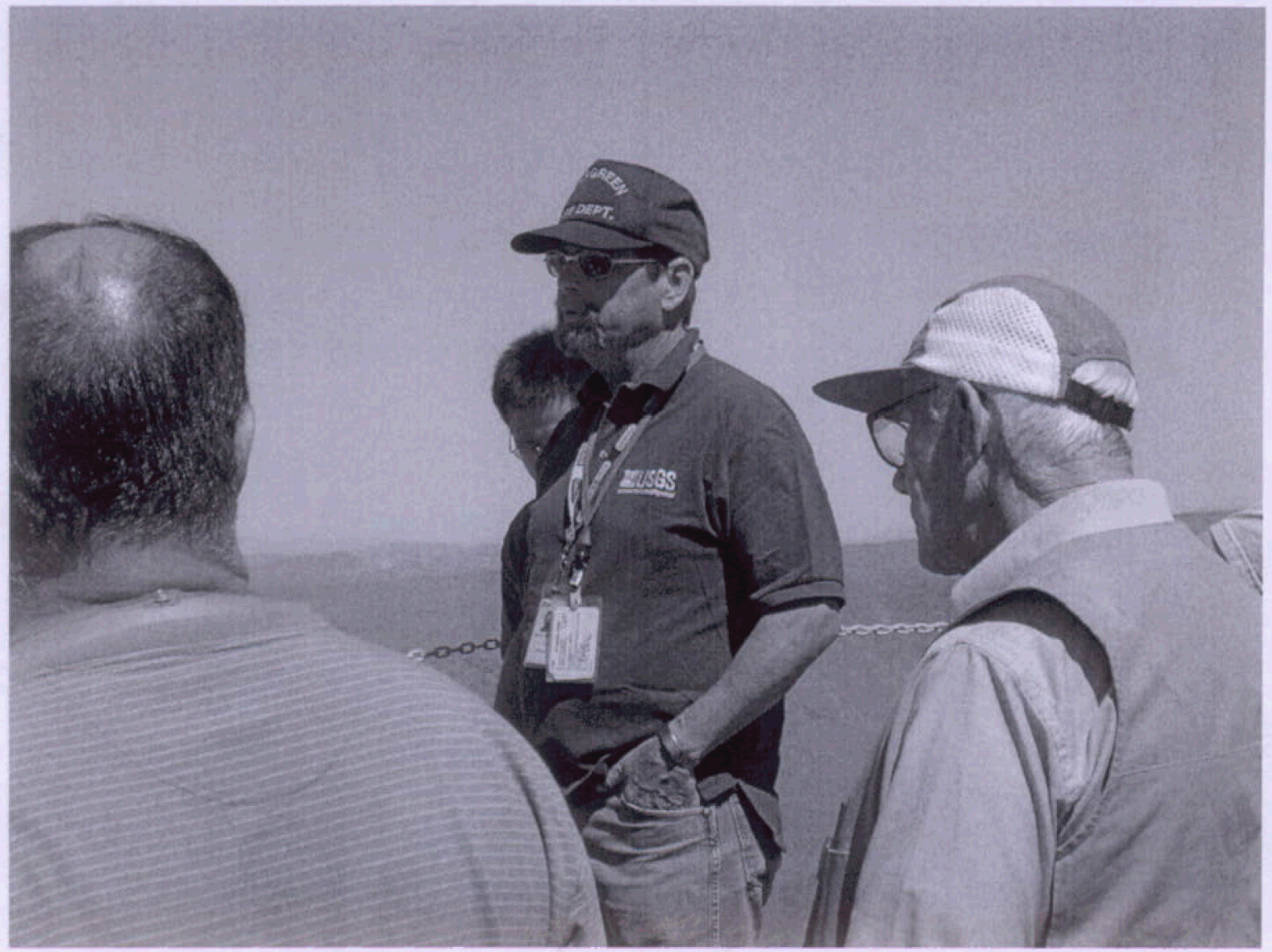

Figure 3. John Stuckless (USGS) lectures to the crew at the top of Yucca Mountain, while the venerable Hu Barnes (Penn State, right) looks on. John and Abe Van Luik (DOE, Yucca Mountain Program Office) proved to be literally inexhaustible sources of information about Yucca Mountain and the greater Las Vegas region. 


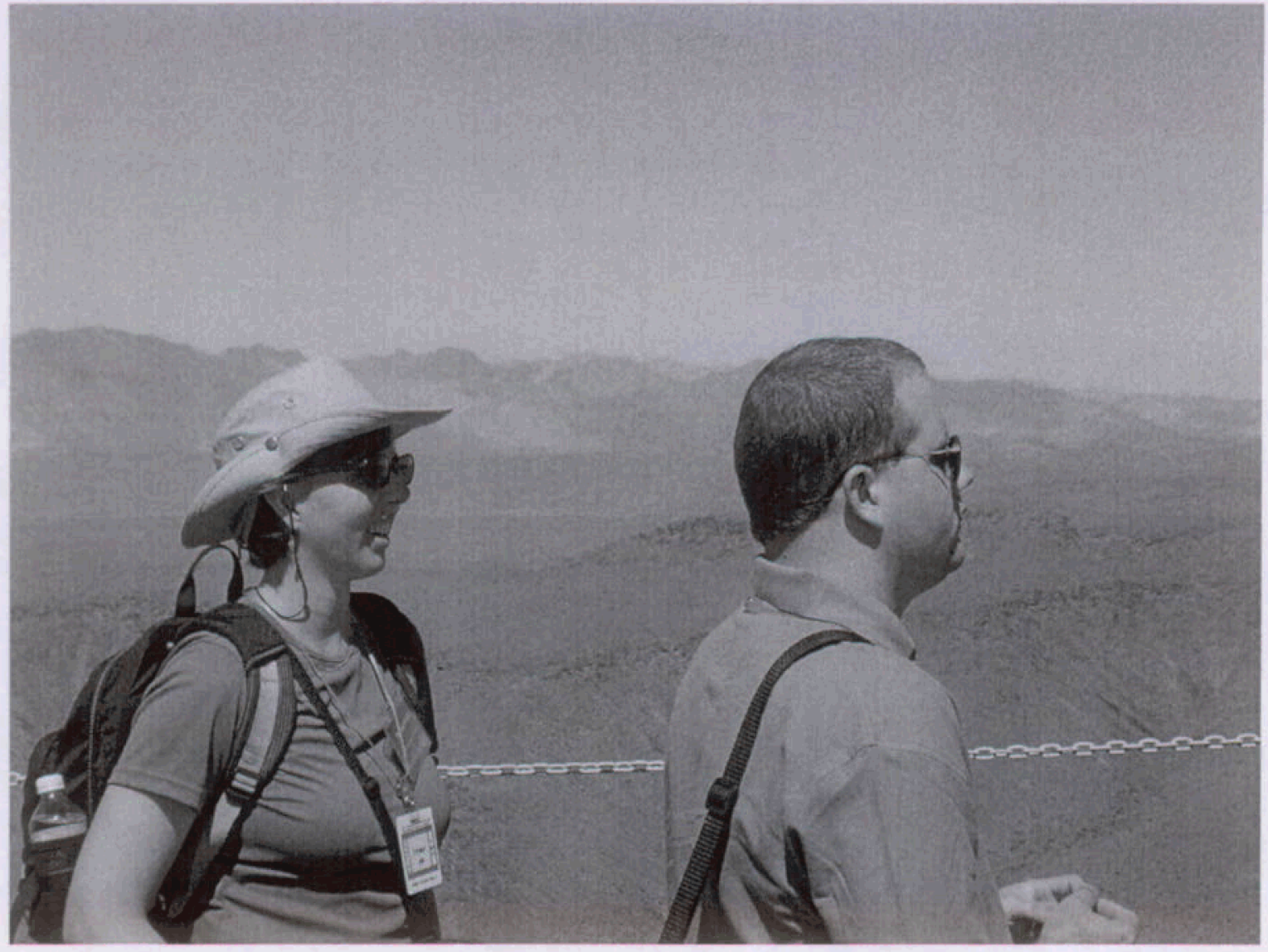

Figure 4. Monique Hobbs (Ontario Hydro) and Jim Wesolowski (University of Tennessee) enjoy the magnificent view toward the distant Sierra's from a vantage point approximately 300 meters above the repository horizon that runs beneath the valley floor below. 


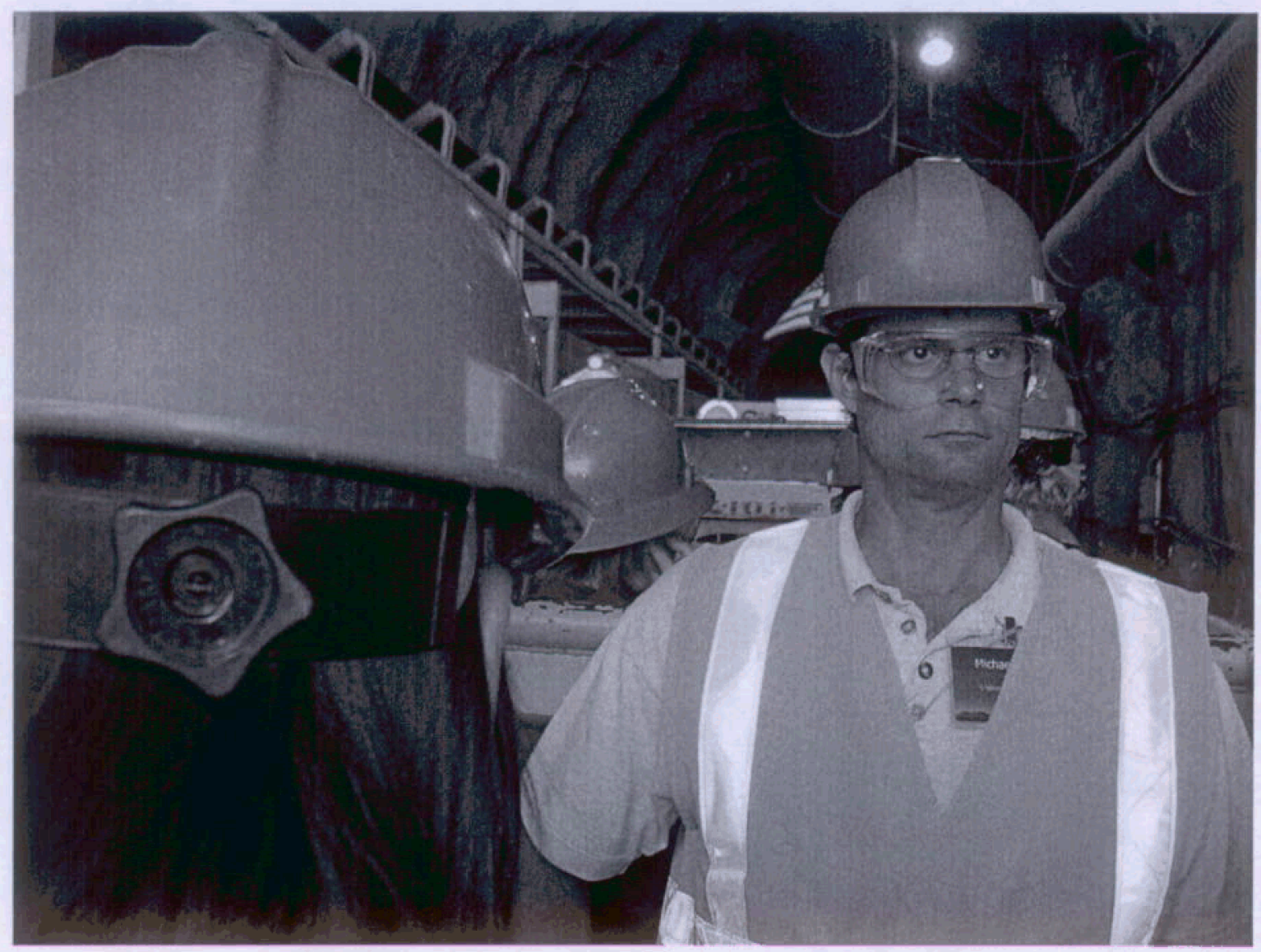

Figure 5. Mike Cosca (University of Lausanne) all suited-up and going underground aboard a diesel train. The $8 \mathrm{~km}$ long main drift (Exploratory Studies Facility) was made by a tunnel borer and is 25 feet in diameter throughout. 


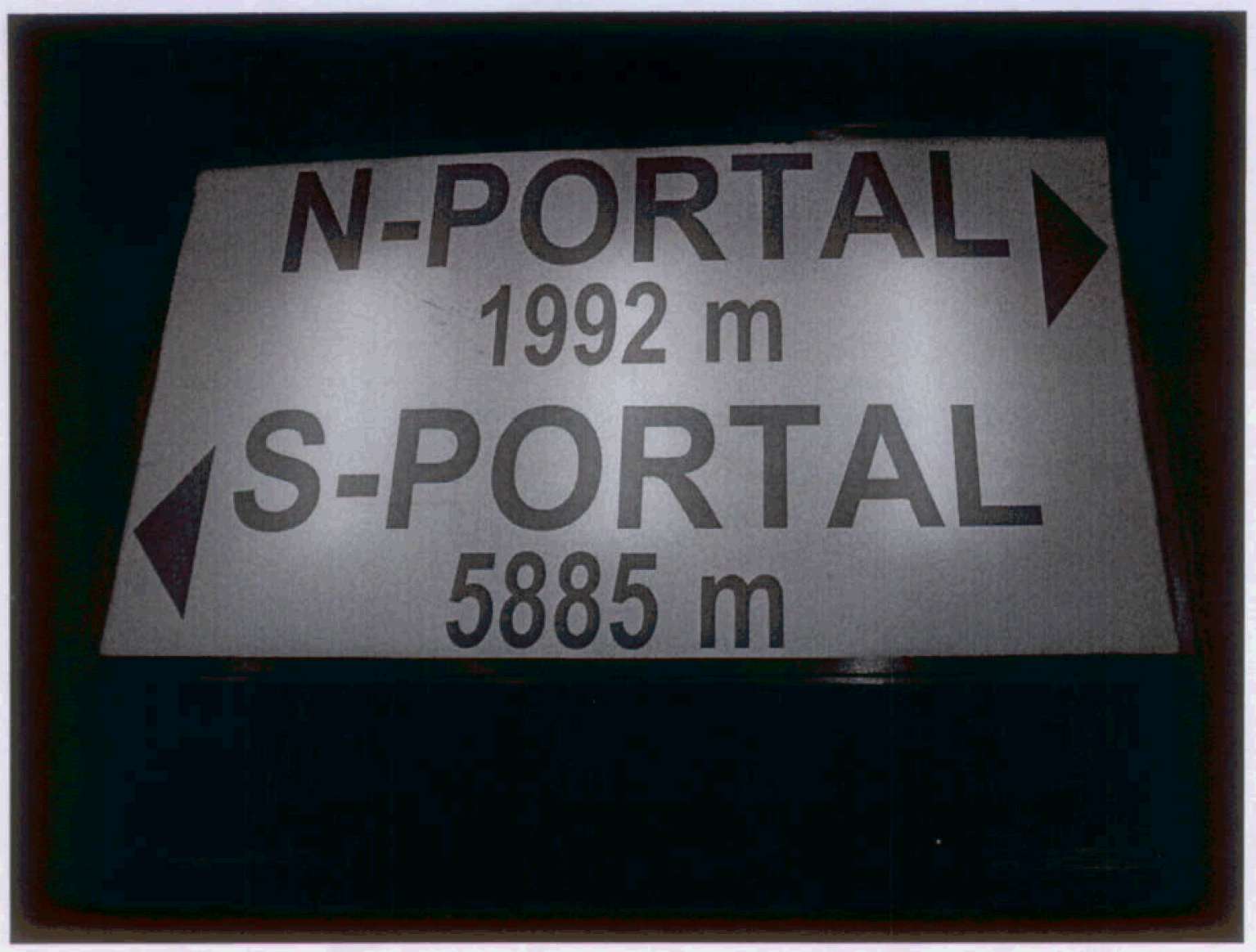

Figure 6. The farthest we got into the main drift before the train's exhaust set off a carbon monoxide monitor. Safety-conscious mine managers sent us packing, but not before we achieved an intimate understanding of the enormity of this engineering and scientific endeavor, so critical to our nation's energy future, and that of the world as well! 